\title{
Comparative Small Business: Toward A Model
}

M. Ruhul Amin, (Email: mamin@bloomu.edu), Bloomsburg University Sharmistha Banerjee, (Email: sharmisthabanerjee@hotmail.com), University of Calcutta, India

\begin{abstract}
This paper addresses the issue of comparability of the small business across geographical boundaries based on organizational contextual, structural variables and the effectiveness indicators. The authors argue that (1) there are already many features, profiles, managerial challenges and the role the small businesses play in a political economy that are common to many countries; (2) the gradual homogenization (due to successful penetration and integration of web based information and transactional technology) of business cultures in a borderless and seamless global business environment may enable tentative generalizations based on empirical as well as ethnographic studies. The paper first defines small business effectiveness and then outlines several common factors through a review of case and ethnographic studies. Finally, the author takes one of the common factors - the issue of capacity utilization and proposes a quasi deterministic empirical econometric model and shares the findings through a secondary analysis of survey data collected from 179 small scale enterprises in West Bengal, India. The findings reflect positively on the efficacy of the model. The authors conclude: the scholarly pursuits such as this are likely to enrich and contribute to the nascent comparative small business literature and enhance the empirical understanding of the small business dynamics. Consequently, a greater homogenization of the global business practices may facilitate more small business to small business transactions within the country specific diverse global business cultures.
\end{abstract}

\section{INTRODUCTION}

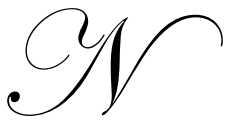

o one debates the statistics affirming the importance of small businesses in the macro economic life of any nation, developed, developing or undeveloped. According to the U.S. Bureau of Labor Statistics (2002), small firms represent 99.7 percent of all employer firms (out of a total of 22.9 million); employ half of all private sector employees; pay 44.3 percent of the total U.S. private payroll; and generate 60 to 80 percent of net new jobs annually. Based on SBA, a little over 2 percent of all firms employ over 100 employees; 85 per cent employ less than 100 employees and 12 percent employs no employees. Although definition of small business size varies from manufacturing (500) to retail (100) to oil refineries (1000); about 85 per cent of the business firms (with 1-99 employees) could be classified as the small business; 12 percent (with no employees) could be genuinely micro businesses; and the 2 percent (with 99 to 500 employees) could be classified as the medium size businesses. Of the small businesses, about 25 percent or 4.6 million firms employ 10 to 99 employees in the United States. Although the businesses also could be classified based on the sales volume or gross revenue, the classification based on the size of employees would probably best fit most countries of the world. This later category of small businesses provides the unique opportunity for a comparative study under structural (Weber, 1968; Child, 1972; Pugh et al., 1968: Blau, 1970), cultural (Cameron and Quinn, 1999; Martin, 2002), environmental (Thompson, 1967; Katz and Kahn, 1978; Pfeffer and Salanick, 1978); population-ecology (Hannan and Freeman, 1979) and a number of other modern perspectives. In addition, organizations with fewer than 10 employees tend to behave similarly as the micro businesses with informal structures and processes and that is why they could be studied and compared together under the clan cultural perspective. (Ouchi, 1981; Lincoln, Hanada, and Olson, 1981; Ott, 1989; Cameron and Quinn, 1999).

The benefits of comparative studies are many. First, in a seamless and borderless business world today, a rapid homogenization of business practices are taking place especially with regard to the transaction, advertising and 
bargaining. The millions of (B2B; B2C; C2C) customers across the continental divides are now transacting through the versatility of the internet and are now using credit cards, Pay Pal, and other approved transaction systems of the first world. Thousands of new business sites are appearing on the World Wide Web from the countries less accustomed to western business practices. Better Business Bureau (BBB), a western consumer protection institution has stepped up in its mission and activities in facilitating cross-country transactions. While dissemination of western business practices are on the rise, the country specific, region specific, language specific business sites are also emerging at a rapid rate. This latter category of businesses has been combining the local, regional and ethnic approaches to business with the western transaction, advertising, and bargaining culture. A browse through the Chinese, the Japanese, and the Hispanic sites may substantiate this point. With increased understanding through comparative studies, collaboration, licensing, franchising, and joint venture, i.e. the hither to strategic options available only to large and medium size businesses may soon be economically viable to the small businesses of the world. Second, the dissemination of legal, cultural, ethnic, and social parameters across national boundaries will foster increased trade, business transactions, and production of goods and services. Third, when the homogenization process (i.e. westernization) reaches it's limit (viz., the implication being that and the small businesses may be more rigid in giving up cultural practices that are not directly tied to profitability for the stated or the unstated reasons of patriotism, parochialism, ethnocentrism, "cultural imperialism" and the like), the comparative literature may be able to capture these country specific characteristics. For instance, bargaining on prices by customer as opposed to one fixed price in South and East Asian Markets may be case in point. Finally, comparative studies will immensely contribute to the literature of small business.

Thanks to the scholars in the previous decades; it is through ethnographic studies of large businesses during the latter part of the twentieth century that we now know so much about the Japanese management styles toady. In fact, many large and medium size businesses in the United States, Canada, and Western Europe incorporated the characteristics of Z corporation (Ouchi, 1981; Gruyter, 1989; Tsurumi, 1989) structure and processes. Just-in Time (JIT) and U-shape production plants adopted in the U.S. and the Western Europe trace their origin in Japan. Similarly, due to confluence of ethnographic studies, and intense business interactions and transactions, large Japanese corporations adopted some of the western business principles and practices especially in the marketing, advertising, and asset disclosures and other areas of legal matters of copyrights, patents, and accounting practices during the last few decades. In addition, the ethnographic studies dealing with the Chinese businesses revealed the ancient Chinese business practices, the socialistic legal framework, and the Western Chinese mix practices in the joint-ventures. In many ex-British colonial counties in Asia and Africa, the businesses demonstrate a mix of western and indigenous business practices. In the small businesses however, the indigenous cultural forces seem to remain more dominant.

In the micro business as well as the businesses that employ 1-10 employees, a noticeable homogeneity of informal practices, birth rate and death rate, and the business challenges may be found across the continental divides. These businesses whether they are in India, Japan, USA, France, or in Spain may face the common and generalized challenges and uncertainties except their respective country specific legal and cultural issues. However, it is possible to develop business typologies based on social, economic, and cultural profiles for comparative studies.

\section{The Model}

As indicated, this paper proposes a comparative model dealing with small businesses that employ 10-100 employees. The proposed model provides an intuitive understanding of how the contextual variables such as environment, size, technology, culture, goals, and strategies impact the structure and processes of the small businesses on the one hand, and how a particular structure impacts the efficiency and effectiveness of the small businesses on the other. Finally, the model attempts to demonstrate the linkage among the contextual, structural, effectiveness and the stakeholder satisfaction variables. The authors used the current literature on organization theory and design to develop the following model: 

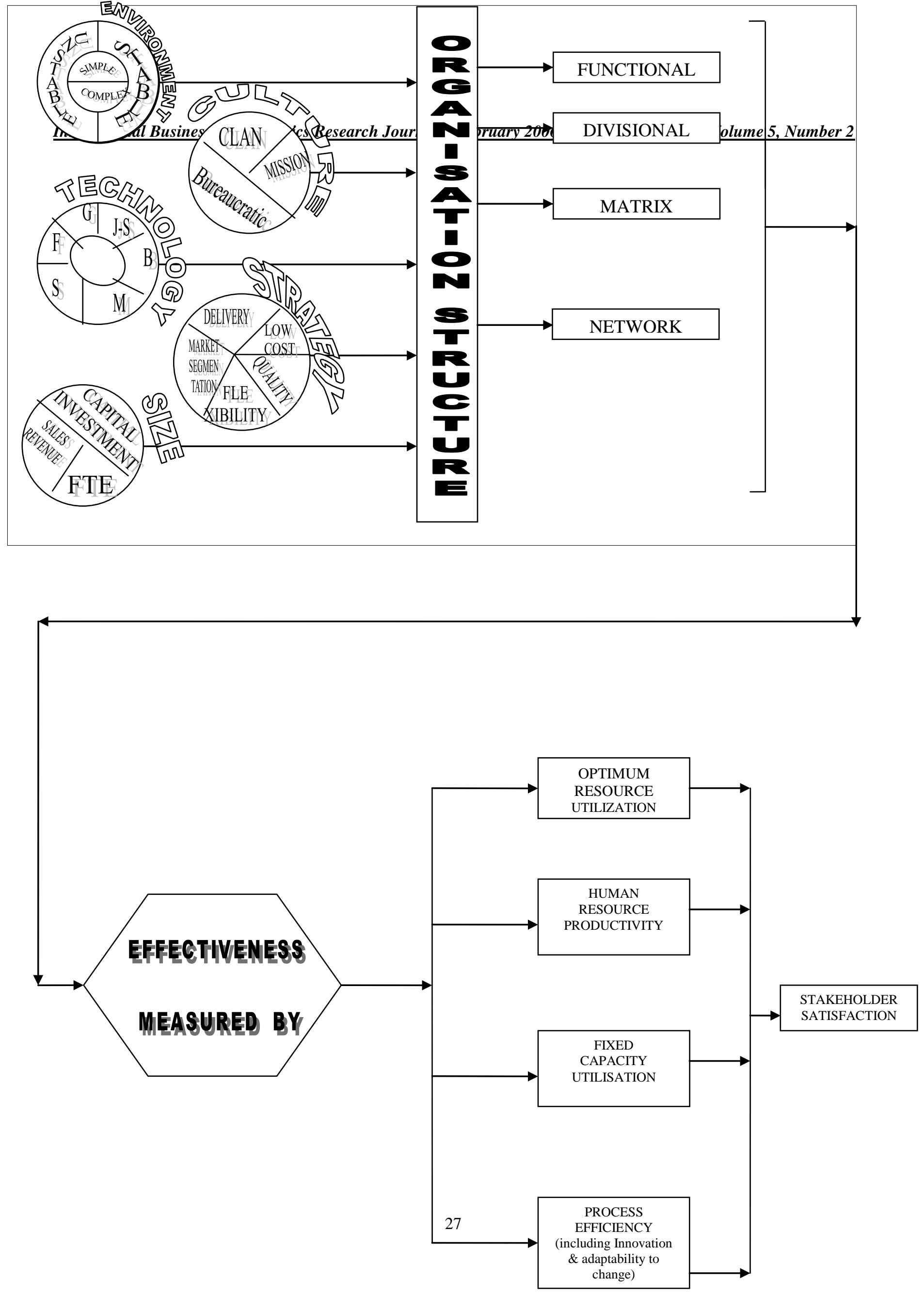
The contextual variables (Daft, 2004; Jones, 2005) include Environment, Technology, Strategy, and the Organizational Size. The environment matrix consists of simple, complex; stable and unstable categories to be measured by their respective indices. As has already been established for large organizations, these contextual variables explain organizational structures such as functional, divisional (mainly product divisions), matrix, and network structures. Again, drawing on the existing literature of organizational effectiveness, five important dimensions have been outlined as the outcome of contextual and structural variables. These include, resource utilization (based on the system resource model, Yuchtman and Seashore, 1967) that includes human resources, technology, capacity, process efficiency and the like. Finally, optimum utilization of resources is expected to contribute to higher return on investment (ROI) and this outcome may lead to stakeholder satisfaction - another key dimension of organizational effectiveness. Satisfaction of both internal and external stakeholders is being proposed in the model.

The above model is a very complex one, designed to provide only a conceptual understanding. It could be developed into a deterministic model through appropriate measurement of variables. A series of testable hypotheses could be developed outlining first the association of each component of the contextual variable with each of the effectiveness dimension; second, a series of hypotheses could also be developed by using each of the structural variables (such as, formalization, complexity, centralization-decentralization, administrative ratio) as intervening factors leading to each of the effectiveness indicators; third, using both structural variables and each of the effectiveness indicators as intervening variables, the association between the contextual variables and the stakeholder satisfaction could be hypothesized.

To test the efficacy of the model, a massive data collection effort is necessary preceded by operationalization of the contextual, structural variables and effectiveness variables. The authors recognize the paucity of data at this point. Construction of indices will be undertaken following a review and refinement of the model. However, using a previous study done by the coauthor, this paper attempts to demonstrate the partial application of this model with data collected from small businesses in the province of West Bengal, India.

\section{THE INDIAN EXPERIENCE:}

A survey method (with $n=179$ ) was utilized to gather information on organizational demographic variables such as size (measured in terms of sales revenue), form of ownership, type of business, and the market characteristics. In addition, information was also collected on the impetus of business ventures, entrepreneurial history, installed capacity and the percentage of installed capacity utilized. The study identifies the variables that explain the rate of capacity utilization, as a measure of effectiveness.

Data used to explain a part of this model, was collected from a survey ${ }^{1}$ of 200 small businesses of West Bengal in 1998 as part of doctoral dissertation project. The 200 sampled units had been distributed over 21 Industry Groups, with unequal weights, weights being distributed among the groups according to their proportion in the total number of units in the state. A survey method was utilized to gather information on organizational demographic variables such as size (measured in terms of sales revenue), form of ownership, type of business, and the market characteristics. $^{2}$ In addition, data was also collected on the impetus of business ventures, entrepreneurial history, installed capacity and capacity utilization rate. The study identified the variables that explain the rate of capacity utilization.

The environmental variables such as the Market Competition is expected to have a bearing on the percentage utilization of capacity. A firm that successfully utilizes more of its fixed capacity, is likely to incur the lowest per unit

\footnotetext{
${ }^{1}$ The Survey was conducted on an all India basis; the section used here was under the leadership of Prof R Khasnabis of Calcutta University. The entire data set is the property of the Department of Business Management, Calcutta University.

${ }^{2}$ While choosing the unit for survey, the rules of Random Sampling could not be honored because of the non-existence of a ready list of units with the concerned district authorities. It was therefore, decided that the selection would follow the method of convenience sampling. As the rules of random sampling were violated, one cannot estimate the Sampling Error and generalization is restricted.
} 
cost. Based on this logic, it can be inferred that the higher capacity utilization would have a positive impact on the stake holder's satisfaction.

Similarly, increased sales measured by Rupees (one of the indicators of organizational size) as a function of the advertisement budget (which is a proxy measure of the marketing strategy) leading to a higher capacity utilization.

A deterministic regression model $^{3}$ was developed based on the following equation:

$C_{u}=\beta_{0}+\beta_{1} L_{u}+\beta_{2} S_{o}+\beta_{3} F_{o}+\beta_{4} F_{b}+\beta_{5} N_{a}+\beta_{6} M_{c}+\beta_{7} A_{y}+\beta_{8} A_{b}+\beta_{9} T_{p l}+\beta_{10} S_{c}+\beta_{11} G_{p l}+\beta_{12} M_{s}$

Where: Capacity Utilization denoted as $\mathrm{C}_{\mathrm{u}}=\mathbf{f}\left[\mathrm{L}_{\mathrm{u}}, \mathrm{S}_{\mathrm{o}}, \mathrm{F}_{\mathrm{o}}, \mathrm{F}_{\mathrm{b}}, \mathrm{N}_{\mathrm{a}}, \mathrm{M}_{\mathrm{c}}, \mathrm{A}_{\mathrm{y}}, \mathrm{A}_{\mathrm{b}}, \mathrm{T}_{\mathrm{pl}}, \mathrm{S}_{\mathrm{c}}, \mathrm{G}_{\mathrm{pl}}, \mathrm{M}_{\mathrm{s}}\right]-----(1)$ Where, $\mathrm{L}_{\mathrm{u}}, \mathrm{S}_{\mathrm{o}}, \mathrm{F}_{\mathrm{o}}, \mathrm{F}_{\mathrm{b}}, \mathrm{N}_{\mathrm{a}}, \mathrm{M}_{\mathrm{c}}, \mathrm{A}_{\mathrm{y}}, \mathrm{A}_{\mathrm{b}}, \mathrm{T}_{\mathrm{pl}}, \mathrm{S}_{\mathrm{c}}, \mathrm{G}_{\mathrm{pl}}, \mathrm{M}_{\mathrm{s}}$ stand for the different independent variables, namely,

$\mathrm{L}_{\mathrm{u}}=$ Location of the unit, $\mathrm{S}_{\mathrm{o}}=$ Sales Revenue, $\mathrm{F}_{\mathrm{o}}=$ Form of Ownership,

$\mathrm{F}_{\mathrm{b}}=$ Family background of the entrepreneur, $\mathrm{N}_{\mathrm{a}}=$ Nature of activity, $\mathrm{M}_{\mathrm{c}}=$ Market characteristics,

$\mathrm{A}_{\mathrm{y}}=$ Advertisement activity, $\mathrm{A}_{\mathrm{b}}=$ Advertisement budget,

$\mathrm{T}_{\mathrm{pl}}=$ Difference between present sales and sales in 1991-92 (Indian economy opened up in 1991-92)

$\mathrm{S}_{\mathrm{c}}=$ Sources of competition faced by the firms, $\mathrm{M}_{\mathrm{s}}=$ Margin on sales, and

$\mathrm{G}_{\mathrm{pl}}=$ Growth in the market since 1991-92 according to the entrepreneur .

The regression model above includes twelve variables; 9 qualitative and 3 quantitative in its set of explanatory variables. The extent to which these variables contribute to the observed variation in the level of capacity utilization of the firms, is proposed to be tested by this regression equation. Ordinarily, with the capacity utilization $\left(\mathrm{C}_{\mathrm{u}}\right)$ as the explained qualitative variable, the regression proposed, assumes a functional relationship. The regression would estimate the beta coefficient (which would include $\beta_{0}$ as the intercept term of the regression model). ${ }^{4}$

Out of the twelve, nine are qualitative variables that have been converted into categories which in this model work as indicator variables. ${ }^{5}$ Following the indicator variable coding scheme, ${ }^{6}$ an entire set of new variables has been generated. Consider for example, the ownership pattern (i.e. $\mathrm{F}_{\mathrm{o}}$ ) of a unit. It is qualitative in nature but here it has been converted into an indicator variable. While doing so, three categories emerged, namely, the category (1) denoting proprietorship units; the category (2) denoting partnership units and the category (3) combines private and public limited companies. ${ }^{7}$ Out of these, in a logistic regression one would serve as the reference category.

\footnotetext{
${ }^{3}$ Banerjee, Sharmistha, Efficiency of Small Scale Units in West Bengal: An Empirical Analysis, Business Studies, Volume XXIV, Number $1 \& 2$, January \& July 2001.

${ }^{4}$ There are however practical problems in running this linear regression. Many of the variables are qualitative in nature. When a qualitative variable appears in the set of explanatory variables one may take recourse to the introduction of categorical explanatory variables in the form of dummy variables. In our case however, this will not solve the problem because the explained variable, capacity utilization $\left(\mathrm{C}_{\mathrm{u}}\right)$, in this case is also a categorical variable. As one may recall, we are considering the model that introduces the 'percentage of installed capacity utilized' as the explained variable. Although percentage is a quantitative variable, in this case the percentage comes not exactly as a specific quantitative value but a range of values, such as less than 30 per cent, within the range of 30 to 50 per cent and so on. The practitioner has no alternative but to turn the explained variable into a categorical variable - a category representing a range of percentage of capacity utilized. Consequently, the regression model has to be reset in terms of a model that includes categories as explained variables. As one knows, such a problem is usually tackled by the practitioners by introducing a logistic regression which is not a simple linear regression. It assumes a log linear relationship involving all the explanatory variables - qualitative as well as quantitative.

${ }^{5}$ Indicator variables are the outcomes of the Indicator Variable Coding Scheme in Logistic Regression.

${ }^{6}$ To give meaningful codes to the indicator variables the standardized indicator variable coding scheme is followed. The values of the independent qualitative variable must be recorded by creating a new set of variables that correspond in some way to the original categories. If the indicator variables are used for coding the coefficients for the new variables represent the effect of each category compared to a reference category.

${ }^{7}$ The units reported to be operating as limited companies and cooperatives have been added together because there were so few respondents in this combined category that their impact if considered separately would not be rewarding. Therefore further
} 
The reference category is the basic category. Out of the categories in a variable, one of them serves as the reference category. In case of the ownership status, the reference category is chosen to be the category (3). The reference category will not be present in the regression results. However, that is the pivot on which the other variables would stand. The estimated coefficient of the other indicator variables shall have to be interpreted with respect to the reference category (to what extent it performs better or worse compared to the reference category). In the SPSS coding scheme that we have followed there is a built-in sub routine that turns categorical variables into indicator variables and by default, it takes one of the independent variables as the reference category (the last one usually is such a variable).

We use the indicator variable coding scheme for creating the new variables, coefficients of which represent the effect of each category compared to a reference category. The coefficient of the reference category is 0 . For example, in the case of ownership value (1) is the indicator variable for the firms under proprietorship, which is coded as 1 , when it exists, and as 0 otherwise. Similarly the value (2) representing partnership, was coded 1 if it exists, and as 0 otherwise. Reference category in both the cases is the value (3) representing private and public limited companies and cooperatives--all added together. Similarly all other qualitative variables have been broken up into sub parts while converting them into indicator variables. As a result, a total of 31 variables have emerged. The three quantitative variables used as independent variables in the regression are sales in Rupees, the advertisement budget (in Rupees) and the margin on sales in percentage terms.

A logistic regression is likely to provide a more powerful explanation than an ordinary linear regression in terms of explaining the probability of 'better or worse performance' of a firm, and in terms of the explained variable (capacity utilization in this case) as a particular explanatory variable becomes operative. For example, as we have proposed in the regression equation, the form of ownership is an explanatory variable. The ordinary regression would estimate the regression coefficient of this variable. It would describe the percentage change in explained variable as a result of a change in the explanatory variable. When the explanatory variable is qualitative, as in case of the form of ownership, the ordinary regression would describe this in terms of a dummy variable (what percentage change will result out of a movement from one category to another). The model that we propose would test whether the change of a particular form of ownership (say from proprietorship to partnership) could contribute to the enhancement (or deterioration) of the extent of the capacity utilized by a firm so that the firm would (or would not) move from one category to the other. The measure is probabilistic. The intensity of this probable effect of such a change in the explanatory variable can be assessed by the value of and the direction of the corresponding regression coefficient.

\section{FINDINGS}

In the regression equation, the cut off for the dependent variable (capacity utilization) has been set at 50 per cent level. The regression attempts to indicate factors that would lead to better utilization of installed capacity, which inter alia, would lead to cost efficiency by way of reduction in overheads and decrease in idle capacity and hence ultimately bring about stakeholder satisfaction. Before interpreting the summary results, the justification behind the statistical exercise is tested by the omnibus test. It tests the null hypothesis that knowing the independents makes no difference in predicting the dependent in logistic regression. The results of the omnibus test (0.021), being less than 0.05 , we reject the null hypothesis that the inclusion of the independent variables is gainful, and it in fact does improve the prediction with regard to capacity utilization. The overall test of significance, in the form of $2 \log$ Likelihood was also performed and the result has been highly in favor of the regression. The power of prediction of this regression (78 percent correct) is robust, giving it an extra element of dependability.

We now consider the results of the regression equation as reported in the table below:

desegregation at this level is not meaningful. However the similar method of compressing variables has also been followed for family background - agriculture and others and the sources of competition - multinationals and smuggled goods. 
Table

\begin{tabular}{|c|c|}
\hline Independent Variable & Coefficient Of Log Odds \\
\hline Sales Revenue & 0.038 \\
\hline Advertisement Budget & 0.413 \\
\hline Margin of Profit & -0.005 \\
\hline Location - Urban & 1.073 \\
\hline Rural & 2.358 \\
\hline Semi Urban & Referral \\
\hline Nature of Activity - Manufacturing & 21.902 \\
\hline Processing & 21.353 \\
\hline Job-shop & 22.282 \\
\hline Servicing & 30.766 \\
\hline Repairing & 22.547 \\
\hline Subcontracting & Referral \\
\hline Family Background - Manufacturing & 1.395 \\
\hline Trade & 0.538 \\
\hline Services & 0.901 \\
\hline Agriculture & Referral \\
\hline Ownership - Proprietary & -0.557 \\
\hline Partnership & -0.587 \\
\hline Company & Referral \\
\hline Sources of Competition - Other Small Firms & 3.718 \\
\hline Large firms & 3.028 \\
\hline MNCs & Referral \\
\hline Market Characteristics- Local & -0.695 \\
\hline State & -1.383 \\
\hline National & -0.099 \\
\hline International & Referral \\
\hline Difference is sales post liberalization -- Increase in Sales post economic liberalization & 0.519 \\
\hline Decrease in Sales post economic liberalization & Referral \\
\hline Advertisement Activity -- Undertaken & -1.206 \\
\hline Not under taken & Referral \\
\hline Growth in market since liberalization -- Decline in growth & 0.184 \\
\hline Stagnation & -0.492 \\
\hline Slow or rapid growth & Referral \\
\hline Constant & -25.327 \\
\hline
\end{tabular}

As the results indicate, the beta coefficient of turnover (sales revenue), as an explanatory variable is positive but very small in magnitude (0.038). This implies that a change in turnover shall have a positive impact on the amount of installed capacity utilization by the firm, but the magnitude of such impact on stakeholder satisfaction is insignificant, probably because the sales revenue is not a direct measure of stakeholder satisfaction. The margin of profit would probably be more meaningful explanatory variable of stakeholder satisfaction. The second quantitative variable is advertisement budget whose corresponding Beta Coefficient has an estimated value of 0.413 which is considerably high. Thus the evidence is in favor of the argument that, the advertisement budget is has a positive impact on the capacity utilization of a firm. The success in the advertisement is likely to promote product differentiation and increase in demand. With product differentiation and increased demand, the firm finds it necessary to optimize its capacity utilization. This leads to profit maximization and the stakeholder satisfaction.

On the location issue, the possibility of utilizing more than 50 per cent of the installed capacity increases as the firm moves from semi-urban to urban and more so when it shifts to rural areas. In the urban segment it enjoys the benefits of external economies of scale due to the existence of better physical infrastructure including a marketing network. On the other hand, in the rural areas, it gets the advantages of the availability of low paid unskilled and semi skilled workers that keeps the wages low, which may neutralize the lack of advantages through external economies 
that the urban units enjoy. This point seems to be important because it may explain the observed rural bias of small scale industrial units in India ${ }^{8}$. The location of a unit therefore is an important measure of the contextual variable influencing efficiency of a small unit.

The variable, nature of activity reflects the kind of technology used in the business to have a strong interrelationship with capacity utilization as the values in the B column, are very large. The results indicate that units involved in activities like manufacturing, processing, job working (job shop), servicing and repairing have higher capacity utilization in comparison to the units engaged in sub-contractual activities. This is probably due to the fact that sub-contracting activities maintain higher idle capacity with the expectations of sudden large orders, which are lucrative. The results also indicate that possibility of better utilization of installed capacity is likely to increase in servicing, repairing, job work (job shop), processing and manufacturing (the reference category being sub contracting). Sub contracting being chiefly an urban activity, the results indicate that the small industries in the rural areas which hardly enter into subcontracting activities are likely to utilize the installed capacity in a better way.

As the result of the regression analysis further indicates, the family background of the entrepreneurs is an important cultural variable explaining the efficiency of such enterprises. The odds of utilizing the installed capacity at more than 50 per cent level increases, had the background of the entrepreneur not been agriculture and the other related activities. In other words, the rural enterprises could be efficient if such businesses are taken up by entrepreneurs having trade or services as family background. This can be conceptualized by considering the existing scenario of rural West Bengal in which there is a high rate of growth in agriculture (around 6.5 per cent for the last one decade), which has created demand for trade, services and manufactured goods. While the big businesses try to explore the prospects in rural market in West Bengal, there still exists a space for the small enterprises.

The units catering to the international market, have higher capacity utilization than those dealing with local, state or national markets. This is again evident from the negative values in the B column corresponding to the variable market characteristics. In the international market, only the most efficient firm would survive. For a firm to operate in the international market, it has to pass the test of efficiency - efficiency considered at the global level. The inefficiency is likely to increase as we consider the firms operating at the state level. The local level firms appear to be somewhat better performers most likely due to the fact that they operate in a sort of captive market that generates steady demand at a reasonable price.

Another environmental variable is the degree of competition the faced by the small units. If we consider the MNCs and the smuggled goods as the reference category, it is observed that the firms are mostly threatened by competition from these sources. The small firms that compete in the product line in which the MNC and the smuggled goods do not find it encouraging to go on increasing capacity utilization possibly because the market is saturated and there is likelihood of inventory accumulation which has negative impact on capacity utilization.

Finally we consider the environmental context with respect to the small enterprises after the introduction of the liberalized economic policy. The respondents were asked two questions, the first about the perception of the market. The answer was supposed to be subjective, indicating how the entrepreneur feels about the market - whether there was a decline, stagnation, or growth in the market. As another proxy indicator of the environment in which the small business operates, the difference in turnover (in sales) compared to what it had been in 1991-92 was also asked. The regression coefficient pertaining to the perception of the respondent about the market behavior since 1991-92 does not have much bearing on the issue of effectiveness. Only thing that should be highlighted is that the entrepreneurs who have a pessimistic outlook about the market were found to be utilizing the installed capacity in a better way. More meaningful however are the results with 'difference between present and 1991-92 sales' as an explanatory variable. There are two categories of firms; those whose volume of turnover had declined after the introduction of the new economic policy and those who had a better business during this period. It was observed that the possibility of better capacity utilization increases with firms having a higher turnover during the period under survey than in 1991-92. This is consistent with what one would normally expect. The new economic policy that opened up the small sector to more competition from national and international sources might have created a negative

\footnotetext{
${ }^{8}$ As per the Census (1998) at an all India level 42.17 per cent of the small scale units are concentrated in the rural sector.
} 
impact for such firms or fail to meet competition. Consequently, their sales has declined (so also the level of profit margin), adversely affecting stakeholder satisfaction. As a result a higher percentage of installed capacity remained idle in such firms. On the other hand, a firm that could meet the challenge could utilize the capacity in a better way and thereby reduce idle capacity.

On the issue of ownership, it seems that the odds of greater capacity utilization do not increase for the proprietary or partnership firms. In fact, the corporate bodies and cooperatives are found to offer better organizational form for pursuing efficiency. Such behavior is probably caused by managerial advantages enjoyed by corporate and cooperatives that operate on the basis of a functionally differentiated form of management. Small enterprises are usually organized in the line of partnership and proprietorship. ${ }^{9}$ The typical form of management in such enterprises is undifferentiated type of management exercised by the entrepreneur.

\section{CONCLUDING OBSERVATIONS ABOUT THE REGRESSION EQUATION}

The operation of units at higher than 50 percent of the installed capacity is a measure efficiency and effectiveness assumed in this study. With the SPSS subroutine logistic regression, using this cut off level, we have been able to get some idea about the factors that might contribute favorably (and also those which contribute unfavorably), to the firms' efficiency and effectiveness.

With respect to the level of capacity utilization (considered in terms of percentage of installed capacity utilized), it was observed that some contextual variables would contribute positively. We have identified factors that are common in the set of explanatory variables.

Based on the analysis above, it can be concluded that no single aspect contributes towards the firms' efficiency and effectiveness. Various firms survive and operate at differing levels of efficiency (i.e. different capacity utilization ratio. Some may only excel through their entrepreneurial qualities. Some others may survive better through exploiting an environmental situation with weak sources of competition. Pure or common sense economics sometimes fail to provide the logic or explanation behind stakeholder satisfaction of such of the small units.

The future direction of the research includes full identification of the model, construction and opeartionalization of the indices; and pilot testing of the various aspects of the model with data collected form several countries.

\section{BIBLIOGRAPHY}

1. Banerjee, Sharmistha, Efficiency of Small Scale Units in West Bengal: An Empirical Analysis, Business Studies, Volume XXIV, Number 1 \& 2, 2001.

2. Blau, Peter, A Formal theory of Differentiations in Organizations, American Sociological Review 25, 201-18, 1970.

3. Cameron, K. S. and Quinn, R. E., Diagnosing and Changing Organizational Culture: Based on the Competitive Values From Framework, Sloan Management Review, 39 (2), 43-57, 1999.

4. Child, J., Organization Structure and Strategies of Control: A Replication of the Aston Study, Administrative Science Quarterly, 17 pp 163-177, 1972.

5. $\quad$ Daft, Richard L., Organization Theory and Design, Thomson, South Western, 2004.

6. Hannan, M. T. and Freeman, J., The Population Ecology of Organizations, American Sociological Review 82, pp 929-964, 1977.

7. Jones, Gareth R., Organizational Theory Design and Change: Texts and Cases, 4 the Edition, Prentice Hall 2005.

8. Katz, D. and Kahn, R. L., The Social Psychology of Organization, John Wiley and Sons, New York, 1978.

9. Lincoln, J. R., Olson, J., and Hanada, M., Cultural Effects on Organizational Structure: The Case of Japanese Firms in the United States, American Sociological Review, 43: 829-847, 1978.

\footnotetext{
${ }^{9}$ In our sample 72 per cent of firms are proprietorship and 16 per cent are partnerships.
} 
10. Lincoln, J. R., Olson, J., and Hanada, M., Cultural Orientations and Individual Reactions to Organizations, Administrative Science Quarterly, 26: 93-114, 1981.

11. Martin, Joanne, Cultures in Organizations, Oxford University Press, New York, 1992.

12. Martin, Joanne, Organizational Culture: Mapping the Terrain, Sage Publications, California, 2002.

13. Ott, J. S., The Organizational Culture Perspective, Dorsey Press, Chicago, 1989.

14. Ouchi, W., How American Business Can Meet Japanese Challenge, Reading: Addison-Wesley.

15. Pascale, R. T. and Athos, A. G., The Art of Japanese Management: Applications for American Executives, Simon and Schuster, New York, 1981.

16. Pfeffer, J. and Salanick, G. R., The External Control of Organization, A Resource Dependence Perspective, Harper and Row, New York, 1978.

17. Pugh, D. S., Hickson, D. J., and et al, Dimensions of Organization Structure, Administrative Science Quarterly, 13, 1, pp 65-91, 1968.

18. Thompson, J., Organizations in Action, Mc Graw Hill New York, 1967.

19. Weber, Max, Economy and Society, translated and Edited by Guenther Ruth and Claus Wittich, New York: Bedminster Press, 1968/1921.

20. Yuchtman, E. and Seashore, S., A Systems Resource Approach to Organizational Effectiveness, American Sociological Review, Vol. 32, pp 891-903, 1967.

\section{NOTES}

